\title{
Glycemic Status and Outcome of Neurological Patients with COVID-19 Admitted at Referral Neuroscience Institute of Bangladesh
}

\author{
Mashfiqul Hasan ${ }^{1}$, Mohammad Atiqur Rahman², Sharmin Chowdhury ${ }^{3}$, Tanvir Haider ${ }^{4}$, \\ Subir Das ${ }^{5}$, KM Ahasan Ahmed ${ }^{6}$, ATM Hasibul Hasan, Mohammad Akter Hossain", \\ Sayeda Parveen Akhter ${ }^{9}$, Maliha Hakim ${ }^{10}$
}

\begin{abstract}
${ }^{1}$ Assistant Professor of Endocrinology, National Institute of Neurosciences \& Hospital, Dhaka, Bangladesh; ${ }^{2}$ Assistant Professor of Endocrinology, National Institute of Neurosciences \& Hospital, Dhaka, Bangladesh; ${ }^{3}$ Medical Officer, Department of Neurology, National Institute of Neurosciences and Hospital, Dhaka, Bangladesh; ${ }^{4}$ Assistant Professor of Community Medicine, National Institute of Neurosciences and Hospital, Dhaka, Bangladesh; ${ }^{5}$ Medical Officer, Department of Neurology, National Institute of Neurosciences and Hospital, Dhaka, Bangladesh; ${ }^{6}$ Junior Consultant of Medicine, National Institute of Neurosciences and Hospital, Dhaka, Bangladesh; ${ }^{7}$ Assistant Professor of Neurology, National Institute of Neurosciences and Hospital, Dhaka,

${ }^{8}$ Assistant Professor of Neurology, National Institute of Neurosciences and Hospital, Dhaka, ${ }^{9}$ Associate Professor of

Biochemistry, National Institute of Neurosciences \& Hospital, Dhaka, Bangladesh; ${ }^{10}$ Professor of Neurology, National Institute of Neurosciences \& Hospital, Dhaka, Bangladesh
\end{abstract}

[Received on: 22 April 2021; Accepted on: 12 May 2021; Published: 1 July 2021]

\begin{abstract}
Background: The presentation of corona virus disease 2019 (COVID-19) may include neurological features and patients with neurological disorders may develop concomitant COVID-19 during pandemic. Hyperglycemia leads to higher propensity to COVID-19 infection with higher disease severity. Objective: To assess the neurological diagnoses, glycemic status and outcome in patients hospitalized primarily for neurological problems and subsequently diagnosed as COVID-19. Methods: This retrospective cohort study was conducted in National Institute of Neurosciences (NINS) \& Hospital, Dhaka, Bangladesh. Patients admitted to adult Neurology ward during April to November 2020 primarily for neurological problems and diagnosed as confirmed COVID-19 (with positive RT-PCR test for COVID-19) were included. The hospital records were reviewed and recorded in a checklist. Outcome of patients referred to COVID-19 dedicated hospitals was obtained over telephone. Results: The study included 85 patients with COVID-19 [median age 60 years (IQR: 45-65); 63.5\% male]. Acute ischemic stroke was the most common neurological diagnosis (32.9\%), followed by acute hemorrhagic stroke and subarachnoid hemorrhage $(22.4 \%$ and $15.3 \%$ respectively). Other neurological diagnoses were meningoencephalitis (7.1\%), Guillain Barre Syndrome (4.7\%), Myasthania Gravis (1.2\%), brain abscess (1.2\%) and intracranial space occupying lesion (1.2\%). Fourteen percent patients had no definite neurological diagnosis, they were admitted for delirium. History of diabetes was present in $18 \%$ patients. The mortality was $27 \%$ and the proportion of mortality was significantly higher in patients known to have DM in comparison to those who were not $(\mathrm{p}=0.012)$. The mean age and proportion of male sex was significantly higher among those who expired. Conclusion: There is high rate of mortality in neurological patients with COVID-19 who have variable neurological diagnosis including stroke, autoimmune disease and cerebral infections. Co-existent diabetes further increases the rate of mortality. [Journal of National Institute of Neurosciences Bangladesh, July 2021;7(2):97-102]
\end{abstract}

Keywords: COVID-19; neurological; glycemic status; outcome

Correspondence: Dr. Mashfiqul Hasan, Assistant Professor of Endocrinology, National Institute of Neurosciences and Hospital, Sher-E-Bangla Nagar, Agargaon, Dhaka-1207, Bangladesh; Email: mashfiqul.hasan@nins.gov.bd; Cell no: +8801816268746 Conflict of interest: There is no conflict of interest relevant to this paper to disclose.

Funding agency: This research project was not funded by any group or any institution.

Contribution to authors: MH, MAR, SC, ATMHH, KMAA were involved in protocol preparation, MH, MAR, TH, SPA, MAH were involved in data collection and literature search, MH, MAR, MAH \& MH were involved in manuscript writing. MH, \& MH involved in preparation and revision of this manuscript.

How to cite this article: Hasan M, Rahman MA, Chowdhury S, Haider T, Das S, Ahmed KMA, Hasan ATMH, Hossain MA, Akhter SP, Hakim M. Glycemic Status and Outcome of Neurological Patients with COVID-19 Admitted at Referral Neuroscience Institute of Bangladesh. J Natl Inst Neurosci Bangladesh, 2021;7(2): 97-102

Copyright: (C2021. Hasan et al. Published by Journal of National Institute of Neurosciences Bangladesh. This article is published under the C-reactive Commons CC BY-NC License (https://creativecommons.org/licenses/by-nc/4.0/). This license permits use, distribution and reproduction in any medium, provided the original work is properly cited, and is not used for commercial purposes. 


\section{Introduction}

The corona virus disease 2019 (COVID-19) pandemic, caused by severe acute respiratory syndrome coronavirus 2 (SARS-CoV-2), is undoubtedly the largest and most severe pandemic since the 1918 influenza pandemic as there are more than 146 million confirmed cases and more than three million deaths worldwide ${ }^{1}$. Although the most common and important presentation of COVID-19 is with respiratory disease, the full clinical spectrum of COVID-19 continues to be described ${ }^{2}$. Preliminary findings from case reports and case series have uncovered neurological manifestations of the disease ${ }^{3}$. Now it is recognized by the World Health Organization (WHO) that the presentation of COVID-19 may include neurological features like agitation, delirium, encephalopathy, meningo-encephalitis, acute disseminated encephalomyelitis (ADEM), stroke, Guillain-Barre syndrome (GBS), impaired sense of smell and taste even without respiratory symptoms ${ }^{4}$. A study from Wuhan, China observed neurological symptoms in more than one third of COVID-19 cases $^{5}$. Although a neurological patient may have co-existent COVID-19 acquired from community or hospital which may not be related to their neurological presentation, suspecting SARS-CoV-2 infection as a differential diagnosis in them may be important to avoid delayed diagnosis or misdiagnosis and to prevent further transmission. On the other hand, hyperglycemia is considered to be one of the risk factors of severe COVID-19 disease and death ${ }^{6}$. It is still unclear whether the neurological manifestations have any relationship to the glycemic status in COVID-19.

The neurological manifestations in COVID-19 can be considered as direct effects of the virus on the nervous system, para-infectious or post-infectious immunemediated disease, and neurological complications of the systemic effects of COVID-197 ${ }^{7}$. It is still unclear how SARS-CoV-2 penetrates the central nervous system (CNS). Hematogenous spread of the virus from systemic to cerebral circulation is one possibility ${ }^{8}$, the other being the dissemination through cribriform plate and olfactory bulb9. It is known that SARS-CoV-2 binds to the angiotensin converting enzyme 2 (ACE2) receptors for entry into the cells ${ }^{10}$. In addition to the vascular endothelium and smooth muscle in brain, ACE2 receptors are strongly expressed in the ventrolateral medulla and the nucleus of the tractus solitarium ${ }^{11,12}$. Nevertheless, damage within the CNS or peripheral nervous system (PNS) might not be caused directly by the virus; rather immune responses to the infection may be responsible behind many neurological complications.
Immune mediated injury is evidenced by elevated expression of the cytokine, monokine induced by gamma interferon and infiltration of monocytes and macrophages in the brain. These findings indicate immune cells and release of cytokines and chemokines may contribute to tissue damage ${ }^{13}$.

Cardiovascular complications are rapidly emerging as a key threat in COVID-19. The virus can cause damage to the endothelial cells which in turn activates the inflammatory and thrombotic cascades ${ }^{14}$. Thrombocytopenia with elevated D-dimer and C-reactive protein in severe COVID-19 are consistent with a virus-associated microangiopathic process ${ }^{15}$. Thus severe COVID-19 may present with stroke especially in the presence of cardiovascular risk factors like diabetes. Several authors have reported higher incidence of severe COVID-19 and mortality in people with diabetes ${ }^{16,17}$. People with or without history of DM are observed to have poor prognosis in COVID-19 if there is hyperglycemia on hospital admission suggesting that hyperglycemia in the very early phase of the disease may play a particular role in determining the seriousness of the prognosis ${ }^{18}$. It is also known that high and aberrantly glycosylated ACE2 in the tissue as a result of uncontrolled hyperglycemia could favor the cellular entry of SARS-CoV- $2^{19}$. Thus hyperglycemia may lead to a higher propensity to COVID-19 infection and a higher disease severity. Furthermore, new-onset diabetes and severe metabolic complications of preexisting diabetes have been observed in patients with COVID-1920,21. Thus there is a bidirectional relationship between COVID-19 and diabetes.

The relationship of neurological manifestations and hyperglycemia in COVID-19 is still illusive. As a matter of fact, both are associated with severe disease. So it may be justified to explore the relationship of these two features in COVID-19 patients who are hospitalized primarily for neurological problems. A better understanding of the neurological manifestations and hyperglycemia in COVID-19 may help to guide the management. In this background, the present study is aimed to evaluate the pattern of neurological presentation with outcome and their relationship with glycemic status in hospitalized COVID-19 patients admitted primarily for neurological problems.

\section{Methodology}

This study was a retrospective cohort study conducted in the National Institute of Neurosciences (NINS) \& Hospital, Dhaka. Patients admitted to adult Neurology ward of NINS during April to November 2020 primarily 
for neurological problems and diagnosed as confirmed COVID-19 (with positive RT-PCR test for COVID-19) were included. The researchers reviewed the hospital records of NINS to identify eligible COVID-19 patients. Their medical records (bed ticket, history sheet, treatment sheet, follow up sheet and nursing records) were retrieved from the record section and investigation reports were sought from laboratory science department of the institute. Any missing or uncertain records were clarified through direct communication with involved patients or their attendants and treating physicians. Demographics, neurological diagnosis, capillary blood glucose records, laboratory findings and outcome were recorded in a checklist. As per hospital protocol, patients were referred to COVID-19 dedicated hospitals as soon as the RT-PCR report for COVID-19 came positive. Outcome of these patients was obtained over telephone. Glycemic status was primarily defined as known diabetes and not known to have diabetes according to the history of previous diagnosis of diabetes and/or past history of treatment for diabetes. Each groups were further subdivided according to capillary blood glucose (CBG) recorded at admission into two groups with a cut-off of at $10 \mathrm{mmol} / \mathrm{L}$. Statistical analysis was performed using IBM SPSS Statistics for Windows version 22.0 (IBM Corp, Armonk, NY, USA). Qualitative data were expressed as frequency and percentage. Quantitative data were expressed as median with interquartile range (IQR) or mean with standard deviation (SD). Comparison between groups was made by the Mann-Whitney U test, unpaired t-test and $\chi 2$ test as applicable. Statistical significance was accepted at $\mathrm{p}=0.05$. Due to retrospective nature of the study, written informed consent could not be taken from the patients or their attendants but verbal consent was taken during outcome measure over phone call. Confidentiality and anonymity of the data was strictly maintained. Prior to the commencement of this study, approval of the institutional review board (IRB) of National Institute of Neurosciences \& Hospital, Dhaka was obtained.

\section{Results}

The study included 85 patients with COVID-19 who were admitted in the neurology in-patient department for primary neurological presentations. The median age of the patients was 60 years (IQR: 45-65) and most frequent age group was $61-70$ years $(29.4 \%)$, followed by $51-60(20.0 \%)$. Male patients were more common (63.5\%). Median duration of hospital stay was 4 days (IQR 2-6) (Table 1).
Table 1: Age, gender and duration of hospital stay of study participants $(\mathrm{n}=85)$

\begin{tabular}{lcc}
\hline Parameters & Frequency & Percent \\
\hline Age Groups (Years) & 5 & \\
- $\leq 20$ Years & 5 & 5.9 \\
- 21 to 30 Years & 6 & 5.9 \\
- 31 to 40 Years & 16 & 7.1 \\
- 41 to 50 Years & 17 & 18.8 \\
- 51 to 60 Years & 25 & 20.0 \\
- 61 to 70 Years & 7 & 29.4 \\
- 70 to 80 Years & 4 & 8.2 \\
- >80 Years & 60 & 4.7 \\
Age (years; Median, IQR) & & $45-65$ \\
Gender & 54 & \\
- Male & 31 & 63.5 \\
- Female & 4 & 36.5 \\
Hospital stay (days; Median, IQR) & & $2-6$ \\
\hline
\end{tabular}

IQR: interquartile range.

Patients came from all around the country, but most were residing in Dhaka (23.5\%) followed by Cumilla, Narayanganj, Manikganj and Laxmipur $(9.4 \%, 7.1 \%$, $4.7 \%$ and $4.7 \%$ respectively) (Table 2 ).

Table 2: Distributions of study participants according to residence $(\mathrm{n}=85)$

\begin{tabular}{lcc}
\hline District of residence & Frequency & Percent \\
\hline Dhaka & 20 & 23.5 \\
Cumilla & 8 & 9.4 \\
Narayanganj & 6 & 7.1 \\
Manikganj & 4 & 4.7 \\
Laxmipur & 4 & 4.7 \\
Others & 43 & 50.6 \\
\hline
\end{tabular}

Acute ischemic stroke was the most common neurological diagnosis in these patients $(32.9 \%)$, followed by acute hemorrhagic stroke and subarachnoid hemorrhage $(22.4 \%$ and $15.3 \%$ respectively). Fourteen percent patients had no definite neurological diagnosis, they were admitted for delirium. Other neurological diagnoses were Meningoencephalitis (7.1\%), Guillain Barre Syndrome (4.7\%), Myasthania Gravis (1.2\%), brain abscess $(1.2 \%)$ and intracranial space occupying lesion (ICSOL, 1.2\%).

Eighteen percent of the patients (15 out of 85) were known to have diabetes. The admission capillary blood glucose $(\mathrm{CBG})$ records were obtained in 53 patients and $25 \%$ of them (13 out of 53 ) had $C B G \geq 10 \mathrm{mmol} / \mathrm{L}$ (Figure I). 
Table 3: Distributions of study participants according neurological diagnosis $(n=85)$

\begin{tabular}{lcc}
\hline Neurological diagnosis & Frequency & Percent \\
\hline Acute ischemic stroke & 28 & 32.9 \\
Acute hemorrhagic stroke & 19 & 22.4 \\
Subarachnoid hemorrhage & 13 & 15.3 \\
Delirium & 12 & 14.1 \\
Meningoencephalitis & 6 & 7.1 \\
GBS & 4 & 4.7 \\
Myasthenia Gravis & 1 & 1.2 \\
Brain abscess & 1 & 1.2 \\
ICSOL & 1 & 1.2 \\
\hline
\end{tabular}

GBS: Guillain Barre syndrome; ICSOL: Intracranial space occupying lesion.

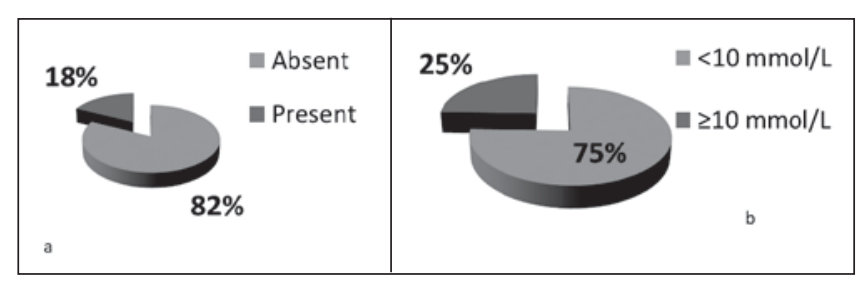

Figure I: Glycemic status of study participants; (a) Presence of past history of diabetes $(n=85)$; (b) $C B G$ on admission $(n=53)$; CBG: capillary blood glucose

Eighteen percent of the patients (15 out of 85 ) were known to have diabetes. The admission capillary blood glucose $(\mathrm{CBG})$ records were obtained in 53 patients and $25 \%$ of them ( 13 out of 53 ) had $\mathrm{CBG} \geq 10 \mathrm{mmol} / \mathrm{L}$ (Figure I).

Among these patients with $\mathrm{CBG} \geq 10 \mathrm{mmol} / \mathrm{L}, 54 \%$ had past history of DM, while $46 \%$ were not known to have DM. On the other hand, $15 \%$ of patients with $\mathrm{CBG}<10$ $\mathrm{mmol} / \mathrm{L}$ had past history of $\mathrm{DM}$, while $85 \%$ did not (table 5).

Table 5: Glycemic status of the study participants according to history of DM and CBG on admission $(\mathrm{n}=53)$

\begin{tabular}{|c|c|c|c|}
\hline \multirow[t]{2}{*}{ Past history of DM } & \multicolumn{2}{|c|}{ CBG on admission $(\mathrm{mmol} / \mathrm{L})$} & \multirow{2}{*}{ P Value } \\
\hline & $<10 \mathrm{mmol} / \mathrm{L}$ & $\geq 10 \mathrm{mmol} / \mathrm{L}$ & \\
\hline $\begin{array}{l}\text { With past history of } \\
\operatorname{DM}(n=13)\end{array}$ & $6(15 \%)$ & $7(54 \%)$ & \\
\hline Without past history of & & & 0.005 \\
\hline $\mathrm{DM}(\mathrm{n}=40)$ & $34(85 \%)$ & $6(46 \%)$ & \\
\hline Total & 40 & 13 & \\
\hline
\end{tabular}

*By $\chi 2$ test; Percentages are on column total; DM: Diabetes mellitus;CBG: Capillary blood glucose

Median CBG was higher in known diabetes group $(\mathrm{p}=0.017)$ (Figure II).

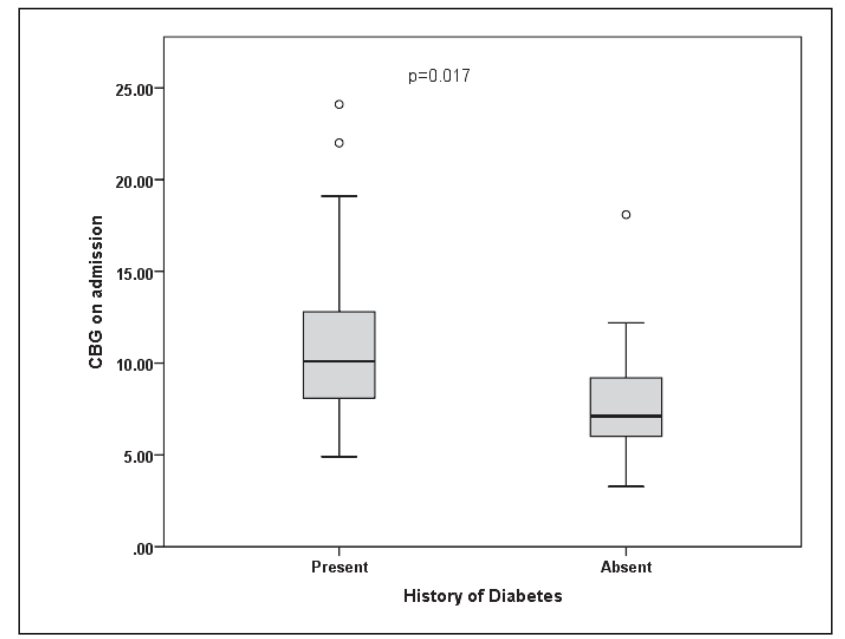

Figure II: Comparison of $\mathrm{CBG}$ on admission between participants with $(n=13)$ and without $(n=40)$ history of Diabetes; CBG: Capillary blood glucose; p-value by Mann-Whitney U test

HbA1c records were obtained in 24 of the study participants (6 known diabetes and 18 not known to have diabetes) and represented in figure- 3 , which shows higher median HbAlc in known diabetes group $(p=0.126)$. Five out of six patients had $\mathrm{HbA1c}>7 \%$ (median 11.5\%, IQR 8-13\%) in known diabetes group. In patients not known to have diabetes, 6 out of 18 patients had $\mathrm{HbA} 1 \mathrm{c} \geq 6.5 \%$ (median $6.2 \%$, IQR 5.8-10.5\%).

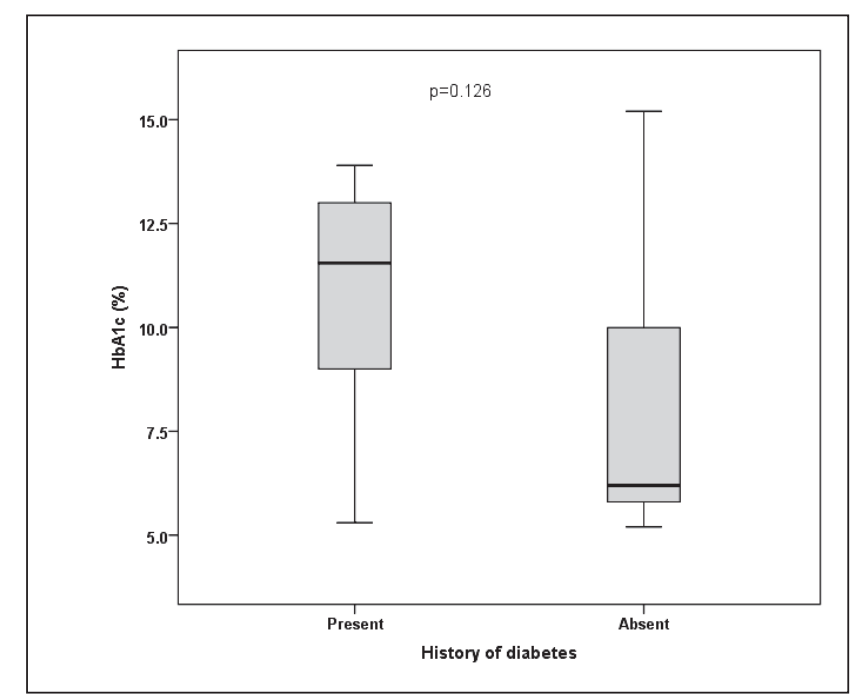

Figure III: Comparison of HbAlc between participants with $(n=6)$ and without $(n=18)$ history of Diabetes; HbAlc: Hemoglobin A1c; p-value by Mann-Whitney U test

Twenty seven percent of patients included in the study expired and the rest $73 \%$ recovered from COVID-19 (Figure IV). 


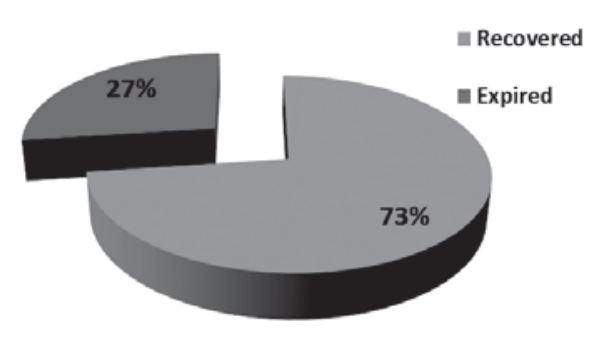

Figure IV: Outcome of study participants $(n=85)$ in terms of mortality

The proportion of patients recovered from the illness were not different between patient groups with or without $\mathrm{CBG} \geq 10 \mathrm{mmol} / \mathrm{L}$ on admission ( $\mathrm{p}=0.693$ ). But the proportion of recovery was significantly lower in patients known to have DM in comparison to those who were not $(\mathrm{p}=0.012)$ and the rate of death was very high among known DM patients (53\%) (Table 6).

Table 6: Comparison of characteristics of the participants according to mortality $(\mathrm{n}=85)$

\begin{tabular}{lccc}
\hline Variables & \multicolumn{2}{c}{ Outcome } & \multirow{2}{*}{ *P Value } \\
\cline { 2 - 3 } & Recovered & Expired & \\
\hline Age $($ mean \pm SD) & $52.0 \pm 18.4$ & $64.7 \pm 11.7$ & 0.003 \\
Sex & & & \\
- Male & $35(65 \%)$ & $19(35 \%)$ & 0.026 \\
- Female & $27(87 \%)$ & $4(13 \%)$ & \\
History of DM & $7(47 \%)$ & $8(53 \%)$ & 0.012 \\
CBG on admission & & & \\
- $\geq 10 \mathrm{mmol} / \mathrm{L}$ & $8(62 \%)$ & $5(38 \%)$ & 0.693 \\
- $<10 \mathrm{mmol} / \mathrm{L}$ & $27(68 \%)$ & $13(32 \%)$ & \\
\hline
\end{tabular}

*By unpaired t-test and $\chi 2$ test; Percentages are on row total; DM: Diabetes mellitus; SD: standard deviation; CBG: Capillary blood glucose

The mean age and proportion of male sex was also significantly higher among those who expired.

Table 7 shows few laboratory parameters of the study participants.

Table 7: Laboratory parameters on study participants

\begin{tabular}{lcccc}
\hline Parameters & n & Median & IQR & Range \\
\hline WBC count (X109/L) & 33 & 12 & $10-15$ & $6-20$ \\
Neutrophil (\%) & 33 & 76 & $68-89$ & $53-92$ \\
Lymphocyte (\%) & 33 & 18 & $10-24$ & $4-40$ \\
Platelet (X109/L) & 33 & 234 & $183-302$ & $132-522$ \\
ESR (mm in 1st hour) & 33 & 24 & $19-51$ & $7-113$ \\
Creatinine (mg/dl) & 39 & 0.88 & $0.71-1.32$ & $0.52-7.86$ \\
\hline
\end{tabular}

IQR: interquartile range

\section{Discussion}

PIn this retrospective study, medical records of eighty five COVID-19 patients were evaluated who were hospitalized primarily for neurological problems. It was observed that this group of patients had a variety of neurological diagnoses; ischemic stroke being the most common of them. The outcomes of the patients were also assessed in this study which was remarkably poor. One in every four study participants died. In patients known to have DM, the mortality rate was even higher (one in every two patients died). The death rate was also higher in male and older patients.

The age and sex distribution of the participants nearly reflects those of hospitalized COVID-19 patients of the country with more predilections for elder age group and male sex, who also had higher death rate in comparison to younger age group and female $\operatorname{sex}^{22,23}$. As the central referral neuroscience institute of the country, people are referred to this center from all over the country. Noticeable participants were residing in and around Dhaka, as this is the area of the country where population density is highest and so is the COVID-19 prevalence.

The neurological diagnosis comprised all types of stroke, few autoimmune neurological syndromes and cerebral infection. Among the different types of stroke, acute hemorrhagic stroke is the most common cause of hospitalization in the study site ${ }^{24}$. But the current study observed higher frequency of ischemic stroke among the study participants. It is beyond the capacity of the present study to establish any cause-effect relationship between COVID-19 positivity and neurological diagnoses. But difference in usual hospital admission pattern and COVID-19 positivity pattern indicates that COVID-19 itself may have precipitated some of the neurological conditions observed in the study especially ischemic stroke. Studies have already identified COVID-19 as an independent risk factor of ischemic stroke ${ }^{25,26}$. Higher proportion of mortality in study participants may reflect the additive effect of COVID-19 over neurological disease or may be related to severe COVID-19 precipitating neurological illness.

The proportion of hyperglycemia in study participants is also comparable to those observed in non-neurological COVID-19 patients reported in a study from Bangladesh $^{27}$. But the mortality rate in patients with diabetes in the current study is much higher than those observed in other studies done in non-neurological COVID-19 cases $^{28}$. Although small number of participants with diabetes in the current study dilutes its significance, the higher rate of poor outcome should 
alert the clinicians and encourage the researchers to carry out further large scale studies.

\section{Conclusion}

There is high rate of mortality in neurological patients with COVID-19 who had variable neurological diagnosis including stroke, autoimmune diseases and cerebral infections. Co-existent diabetes further increases the rate of poor outcome.

Acknowledgements: We acknowledge Dr. Md. Abdullah Yusuf, Associate Professor, Department of Microbiology, National Institute of Neurosciences \& Hospital, Dhaka, Bangladesh for his generous support and technical advice to carry out the study. All the clinical and laboratory staffs of NINS are also acknowledged.

\section{References}

1. World Health Organization. COVID-19 weekly epidemiological update, 25 April, 2021.

2. Neurol L. The neurological impact of COVID-19. Curr Opin Immunol. 2020;62:106-22.

3. Montalvan V, Lee J, Bueso T, De Toledo J, Rivas K. Neurological manifestations of COVID-19 and other coronavirus infections: A systematic review. Clinical Neurology and Neurosurgery. $2020 \mathrm{Jul}$ 1;194:105921.

4. World Health Organization. Clinical management of COVID-19: interim guidance, 27 May 2020. World Health Organization; 2020.

5. Mao L, Jin H, Wang M, Hu Y, Chen S, He Q, Chang J, Hong C, Zhou Y, Wang D, Miao X. Neurologic manifestations of hospitalized patients with coronavirus disease 2019 in Wuhan, China. JAMA neurology. 2020 Jun 1;77(6):683-90.

6. Sardu C, D’Onofrio N, Balestrieri ML, Barbieri M, Rizzo MR, Messina V, Maggi P, Coppola N, Paolisso G, Marfella R. Outcomes in Patients With Hyperglycemia Affected by Covid-19: Can We Do More on Glycemic Control?. Diabetes Care. 2020 May 19.

7. Ellul M, Benjamin L, Singh B, Lant S, Michael B, Kneen R, Defres S, Sejvar J, Solomon T. Neurological Associations of COVID-19. Available at SSRN 3589350.2020 Apr 24.

8. Baig AM, Khaleeq A, Ali U, Syeda H. Evidence of the COVID-19 virus targeting the CNS: tissue distribution, host-virus interaction, and proposed neurotropic mechanisms. ACS chemical neuroscience. 2020 Mar 13;11(7):995-8.

9. Netland J, Meyerholz DK, Moore S, Cassell M, Perlman S. Severe acute respiratory syndrome coronavirus infection causes neuronal death in the absence of encephalitis in mice transgenic for human ACE2. Journal of virology. 2008 Aug 1;82(15):7264-75.

10. Yan R, Zhang Y, Li Y, Xia L, Guo Y, Zhou Q. Structural basis for the recognition of SARS-CoV-2 by full-length human ACE2. Science. 2020 Mar 27;367(6485):1444-8.

11. Hamming I, Timens W, Bulthuis ML, Lely AT, Navis GV, van Goor H. Tissue distribution of ACE2 protein, the functional receptor for SARS coronavirus. A first step in understanding SARS pathogenesis. The Journal of Pathology: A Journal of the Pathological Society of Great Britain and Ireland. 2004 Jun;203(2):631-7.

12. Palasca O, Santos A, Stolte C, Gorodkin J, Jensen LJ. TISSUES 2.0: an integrative web resource on mammalian tissue expression. Database. 2018 Jan 1;2018.

13. Xu J, Zhong S, Liu J, Li L, Li Y, Wu X, Li Z, Deng P, Zhang J, Zhong N, Ding Y. Detection of severe acute respiratory syndrome coronavirus in the brain: potential role of the chemokine mig in pathogenesis. Clinical infectious diseases. 2005 Oct 15;41(8):1089-96.

14. Varga Z, Flammer AJ, Steiger P, Haberecker M, Andermatt R, Zinkernagel AS, Mehra MR, Schuepbach RA, Ruschitzka F, Moch H. Endothelial cell infection and endotheliitis in COVID-19. The Lancet. 2020 May 2;395(10234):1417-8.

15.Li Y, Wang M, Zhou Y, Chang J, Xian Y, Mao L, Hong C, Chen S, Wang Y, Wang H, Li M. Acute cerebrovascular disease following COVID-19: a single center, retrospective, observational study.

16. Guan WJ, Ni ZY, Hu Y, Liang WH, Ou CQ, He JX, Liu L, Shan H, Lei CL, Hui DS, Du B. Clinical characteristics of coronavirus disease 2019 in China. New England journal of medicine. $2020 \mathrm{Apr}$ 30;382(18):1708-20.

17. Zhou F, Yu T, Du R, Fan G, Liu Y, Liu Z, Xiang J, Wang Y, Song $\mathrm{B}, \mathrm{Gu} \mathrm{X}$, Guan L. Clinical course and risk factors for mortality of adult inpatients with COVID-19 in Wuhan, China: a retrospective cohort study. The lancet. 2020 Mar 11.

18. Iacobellis G, Penaherrera CA, Bermudez LE, Mizrachi EB. Admission hyperglycemia and radiological findings of SARS-COv2 in patients with and without diabetes. diabetes research and clinical practice. 2020 Jun $1 ; 164$

19. Brufsky A. Hyperglycemia, hydroxychloroquine, and the COVID-19 pandemic. Journal of Medical Virology. 2020 Apr 15.

20. Rubino F, Amiel SA, Zimmet P, Alberti G, Bornstein S, Eckel RH, Mingrone G, Boehm B, Cooper ME, Chai Z, Del Prato S. New-Onset Diabetes in Covid-19. New England Journal of Medicine. 2020 Jun 12.

21. Li J, Wang X, Chen J, Zuo X, Zhang H, Deng A. COVID-19 infection may cause ketosis and ketoacidosis. Diabetes, Obesity and Metabolism. 2020 Apr 20.

22. Hossain H, Chowdhury T, Majumder M, Ava A, Rahman QA, Md Zahiruddin -, Ahasan H, Islam Q. Demographic and Clinical profile of 190 COVID-19 Patients in a Tertiary Care Private Hospital of Dhaka, Bangladesh: An Observational Study. JOM [Internet]. 9Nov.2020 [cited 29Apr.2021];21(2):82-8. Available from: https://www.banglajol.info/index.php/JOM/article/view/50210

23. Mamun SA, Noor M, Jahan R, Khan S. Demographic and Clinical profile of COVID- 19 Patients in a Tertiary Care Private Hospital of Dhaka, Bangladesh: An Observational Study. BJM [Internet]. 4Jan.2021 [cited 29Apr.2021];32(1):25-0. Available from: https://www.banglajol.info/index.php/BJMED/article/view/51091 24.Chowdhury MT, Choudhury MSJ, Ahmed K, Sarkar MS, Yusuf MA, Haider T, Alam MB. Trend of Hospital Admission and Outcome Study of Patients Admitted in a Neurology Unit at a Tertiary Care Neuroscience Hospital in Bangladesh. JNINB [Internet]. 10Dec.2018 [cited 29Apr.2021];4(2):69-4. Available from: https://www. banglajol.info/index.php/JNINB/article/ view/38917

25.Belani P, Schefflein J, Kihira S, Rigney B, Delman BN, Mahmoudi K, Mocco J, Majidi S, Yeckley J, Aggarwal A, Lefton D. COVID-19 is an independent risk factor for acute ischemic stroke. American Journal of Neuroradiology. 2020 Aug 1;41(8):1361-4.

26.Zhai P, Ding Y, Li Y. The impact of COVID-19 on ischemic stroke. Diagnostic Pathology. 2020 Dec;15(1):1-5.

27.Akter F, Mannan A, Mehedi HH, Rob MA, Ahmed S, Salauddin A, Hossain MS, Hasan MM. Clinical characteristics and short term outcomes after recovery from COVID-19 in patients with and without diabetes in Bangladesh. Diabetes \& Metabolic Syndrome: Clinical Research \& Reviews. 2020 Nov 1;14(6):2031-8.

28. Morshed MS, Al Mosabbir A, Hossain MS. Comparing between survived and deceased patients with Diabetes Mellitus and COVID-19 in Bangladesh: A cross sectional study from a COVID-19 dedicated hospital. medRxiv. 2021 Jan 1. 